\title{
The Effect of Peer Collaboration with ViLLE on Success in Financing Mathematics
}

\author{
Matti Kuikka, Mikko-Jussi Laakso \\ Turku University of Applied Sciences, Finland \\ University of Turku, Finland
}

\begin{abstract}
In this paper, we describe how collaborative use of an electronic assessment tool improves students' learning results in Financing Mathematics in higher education. Financing Mathematics was taught as part of the Business Mathematics course in the first year studies for Bachelor's degree students in the International Business program at Turku University of Applied Sciences. The assessment was carried out with the collaborative educational tool ViLLE.

The Business Mathematics course consists of Business Statistics and Financing Mathematics. The Financing Mathematics course component was used for the purpose of this research. In the Business Statistics course component, the students worked independently, whereas in Financing Mathematics, the students also worked in pairs with the tool. The independently working students formed the control group and the students working in pairs formed the treatment group in this quasi-experimental study.

The paper reveals that students working in pairs with the ViLLE tool achieved better exam results than the students working independently. This finding is in agreement with the findings of similar research studies on programming. The collaboration between students seems to be the key reason for the better results of the students working in pairs in this paper.
\end{abstract}

\section{Introduction}

The use of assessment is important in order to evaluate students' learning. Students may verify their skills in formative assessment while studying. The formative assessment may be performed in the class room sessions with teachers' feedback. However, nowadays a large amount of formative assessment is carried out with the help of electronic tools. Electronic assessment (e-assessment) tools are capable of performing instant marking of the assignments, enabling students to receive feedback on their learning while studying.

Students may also collaborate while studying. Electronic tools offer new possibilities for collaboration. Assessment of pair work can be carried by individual students (self-assessment), by pair students (peer assessment), or by teachers. Conejo et al. [2] use the term Collaborative Testing to describe the situation where students do tasks together utilizing an e-assessment tool.

A wide range of studies on collaborative learning has been carried out. The collaboration may be enhanced with the help of electronic tools. Several papers have been written about pair work with electronic assessment tools [2, 3, 5, 9, 10]. These papers have mostly focused on the effect of pair work in order to learn to program. Collaborative use of electronic tools has been shown to improve learning in programming. However, there is hardly any research addressing collaborative work with electronic assessment tools for business mathematics in higher education.

This article describes how collaborative testing with the e-assessment tool ViLLE affects students' learning results in financing in a Business Mathematics course. The course was run at Turku University of Applied Sciences in the spring of 2014. This article provides an answer to the following question: Does working in pairs with the eassessment tool affect students' success in exams?

The paper is structured as follows: First, the relevant related work is presented, followed by an introduction to the ViLLE tool. Then the methods used, the research set-up, and the procedures are described. Finally, the results, discussion, and conclusions are presented.

\section{Related work}

The benefits and methods of performing collaborative computer-based learning and assessment have been discussed in several publications [1, 4, 7, 10]. In addition to learning, collaboration improves students' skills in areas such as communication, critical thinking, creativity, decision-making and problem-solving. The success of pair work as such is not widely discussed in these publications.

Hahn et al. [3] studied how pair programming could be assessed. They compared how the student's own evaluation, peer evaluation and the teacher's 
marking correlated with that of students working in pairs. The students did work in rounds where students first self-evaluated their own work. Then the peer evaluations by the students working in pairs were performed. In the first round of the assessment, the pairs' markings were better than the students' own markings, but after working in four assignment rounds in pairs, the students' self-evaluations were in line with the peers' evaluations. This indicates that after students have become more familiar with peer assessment, the students start to provide more realistic evaluations for their pairs. Due to the usage of the peer assessment, the students also worked together more and, therefore, achieved better results in the actual exams conducted by the teacher. Therefore, it can be concluded that pair work improved the learning in programming.

Maguire et al. [8] studied collaborative learning with pair programming as well. They used a method where random pairs were changed weekly. They did not find any clear correlation between pair programming and learning for all students, but they found that female students seem to benefit more from pair programming. Additionally, they found that if the students working in pairs have similar skill levels, they learn better compared to the pairs in which the students have large differences in skill levels. Therefore, Maguire et al. suggest that pairs should be created randomly within clustered groups where the clusters are formed based on students' skill levels.

Conejo et al. [2] researched collaborative testing in a web-based environment called Siette (siette.org) with various course subjects ranging from Computer Sciences to Botany. Conejo's study used the following method: the students first individually answered a question in the system. Then students working in two-student or three-student groups discussed the questions and answers. Then the students completed the same task individually. Conejo et al. remarked that the students' second answers received higher scores than the initial ones and the final answers correlate significantly with the actual correct answers. They also found that lowperforming students benefit more from the collaborative work.

Rajala et al. [9] studied how the usage of program visualization in collaboration with the ViLLE tool affected learning in programming. They found that students working in pairs with the program visualization spent more time on assignments than students working independently. The amount of discussions students had about the assignments seemed to be the reason for the time increase. Therefore, the students working in pairs achieved better results. This was most effective for difficult exercises, and, therefore, pair work should be applied especially for demanding assignments in order to gain better learning results.
Kaila et al. [5] studied how students' results were improved after an introductory programming course was redesigned. The redesign in the course included the usage of the ViLLE tool. Half of the lectures were replaced with sessions where students worked in pairs with ViLLE tutorials. The results were compared with those of the previous version of the course that was run with lecturing and without pair work. The results of the paper demonstrate that the students' pass rates in the course were improved significantly. However, the average grade remained the same in comparison with the previous course.

It is worth noting here that there is a publication about the overall effect of the ViLLE tool on Business Mathematics learning using the course described in this study [6]. This related study compared the students' grades and feedback between the 2014 course and the previous 2013 course when the course was arranged without the ViLLE tool. Kuikka et al. confirmed the positive effect of ViLLE tool students' overall course results. Additionally, the course feedback was improved.

\section{The ViLLE tool}

ViLLE (villeteam.fi) was used as the electronic assessment tool for the Business Mathematics course examined in this paper (see Figure 1). ViLLE is an exercise-focused learning environment created for research and learning purposes originally for programming at the University of Turku. Teachers can create courses, exercises, tutorials and exams with ViLLE.

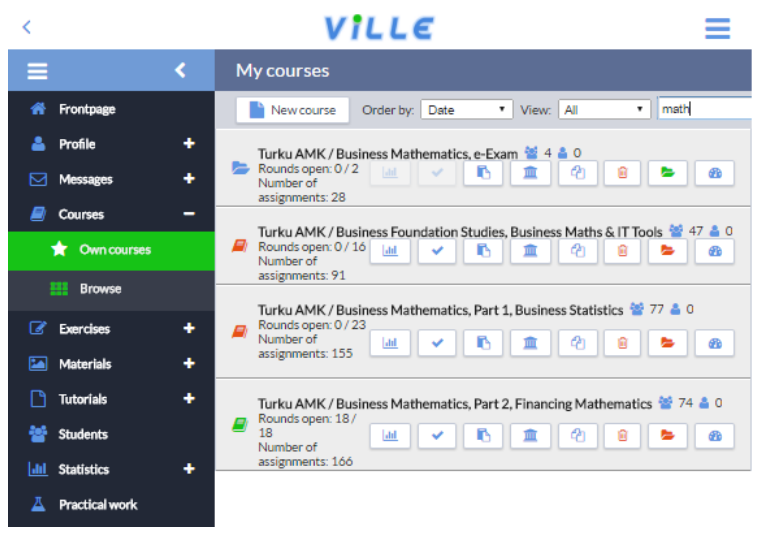

Figure 1. ViLLE tool

ViLLE provides features for learning and assessment such as peer reviews with teacherdefined feedback forms, RFID-based attendance control, course news, discussions and learning diaries. Teachers may also use ViLLE in order to collect course feedback and for polls during the classes. The status and results of the course assignments can be viewed by teachers via the 
statistics function that allows teachers to export data for further processing with other tools.

All the exercises in ViLLE are public. This enables teachers to benefit of the creativity of other teachers: Teachers may use the public exercises as such or modify them according to their needs. Teachers may also collaborate with each other's in the ViLLE environment: Teachers may provide feedback about the exercises they utilize, for example. This provides the teachers with opportunity to improve their exercises because of the collaboration.

When teachers create their own exercises, they may select among ready-made exercise templates that are divided into four main categories. The categories are available for coding, mathematics, educational games and general exercise types (see Figure 2).

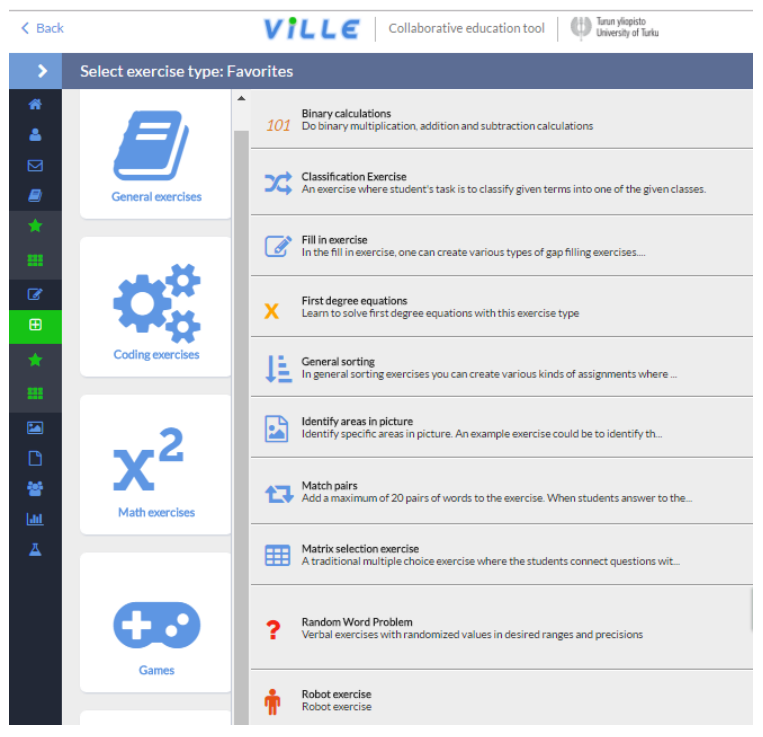

Figure 2. ViLLE tool - Create exercise view

The created exercises can be used for all kinds of assessments either independently or collaboratively. ViLLE provides immediate feedback for the exercises enabling the students to review their learning while studying. The feedback may include additional guidance on the correct answer should the course teacher wish so.

\section{Method}

In this paper, we study the effect of pair work with the ViLLE tool on the course results in the Business Mathematics course for the Bachelor's degree at Turku University of Applied Sciences.

\subsection{Business Mathematics course}

The Business Mathematics course belongs to the curriculum of the Bachelor's degree program in International Business at Turku University of Applied Sciences. The course consists of two course parts. Part 1 deals with Business Statistics and Part 2 covers Financing Mathematics. The course components were originally two separate courses. These courses were merged in one single Business Mathematics course in 2011. However, the course components are still studied separately. For instance, there were separate courses in ViLLE for both components and students received separate grades for Statistics and Financing in addition to the overall grades for Business Mathematics.

The course was run from week 2 until week 12 during 2014. There were 2-hours lectures each week. Additionally, there were two times 2-hour exercises sessions in computer labs from week 3 until week 11. In the Business Statistics, the students worked independently with the exercises. The pair work method was applied to the Financing Mathematics.

The data collected from Financing Mathematics was used for this study. This course component covered mathematical calculations for trading, interests, investments, loans and annuities. In order to evaluate the effect of ViLLE on pair work, the grades and the results of the completed assignments of the students who worked independently were compared with those of the students who worked in pairs.

\subsection{E-assessment with the ViLLE tool}

The exercises in ViLLE were used for formative and summative assessments during the course. All the assignments were provided using the tool (see Figure 3).

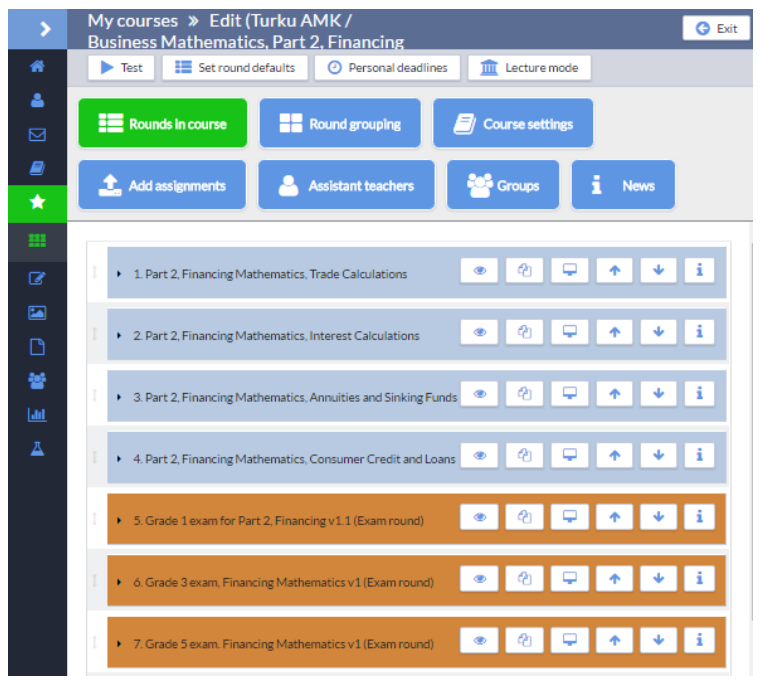

Figure 3. Usage of ViLLE for Financing Mathematics 
The Financing Mathematics course in ViLLE contained rounds that were either the normal or exam rounds. The used exercises were tied to the rounds. Students received the feedback for the exercises in the normal rounds after the completing them. Most of this feedback was based on automatic functionality of the ViLLE tool for the exercise types. Additionally, teacher provided exercise specific feedback with ViLLE using written guidance or linked videos as examples.

The ViLLE tool enabled teacher to create the required assessment environment. Concerning the exams, in ViLLE there were separate exams for each evaluation level: Satisfactory skills: grade 1 exam, Good skills: grade 3 exam, Excellent skills: grade 5 exam (see Figure 4).

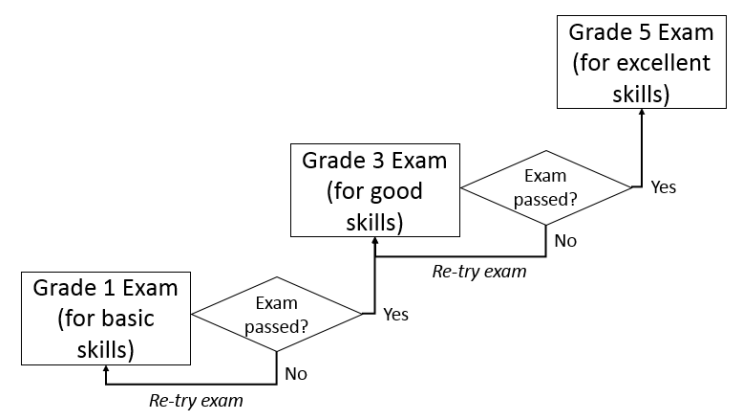

Figure 4. Course examination process

The students were able to try the grade 1 exam three times, the grade 3 exam two times and the grade 5 exam once. The students also needed to pass the previous level exam before they could attempt the exam at the next level.

The students were able to improve their grade by doing assignments. For instance, if a student passed the grade 1 exam (but not the grade 3 exam) and completed $80 \%$ of the assignments, he/she achieved grade 2 .

\subsection{Participants}

Totally 73 students took part in the 2014 Business Mathematics course, but 71 students completed the Financing Mathematics component. In addition to the Bachelor's degree students, exchange students took part in the course. Most of the students were international students: Twenty-four students were Finns and forty-seven students were international students. The students from Vietnam, Nepal, Russia and China were mostly represented among the international students. The course was taught in English that was not the teacher's native language.

The course participants consisted of 40 males and 31 females, and the age range of the majority of the participating students was between 20 and 23 years.
Most of the students were students in the Degree Program in International Business.

When the students worked with Financing Mathematics in Part 2, they had the opportunity to choose to work in pairs with the assignments instead of doing them independently. The pairs were selected by the students themselves.

\subsection{Procedure}

The exam successes of the students working independently and in pairs were compared to find the effect of collaboration (see Figure 5). The independently working students formed the control group and the students working in pairs formed the treatment group. The students were able to change pairs between the exercise sessions, and the students working in pairs were also able to work independently with the exercises.

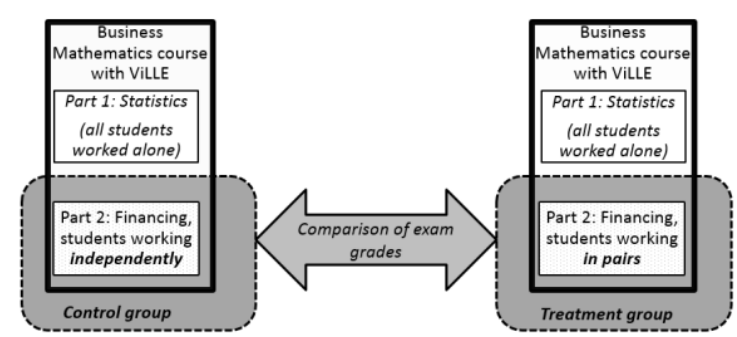

Figure 5. Comparison of the effect of pair work

First, we analysed how the students succeeded in the exams by comparing the ratio of the students passing the grade 5, the grade 3 and the grade 1 exams. We also examined the ratio of the students failing all the exams, and the average percentage of assignments completed by the groups.

In addition, the differences of success of the control and treatment groups at the first attempts for the grade 1 and 3 exams were analysed.

Then we compared how gender affected pair work, and how the results of Finnish and international students differed between independently working students and students working in pairs. We also analysed the amount of submissions and the time spent with the assignments between these student groups.

\section{Results}

Thirty-one students worked in pairs and forty students worked independently in Part 2. The students working in pairs achieved better results measured both in terms of number of assignments completed and success in the exams (see Table 1). 
Table 1. Effect of pair work on passing the exams for Financing Mathematics

\begin{tabular}{|c|c|c|c|c|}
\hline \multirow{2}{*}{} & \multicolumn{2}{|c|}{$\begin{array}{c}\text { Working } \\
\text { independently } \\
\text { (N=40) }\end{array}$} & \multicolumn{2}{c|}{$\begin{array}{c}\text { Working in } \\
\text { pairs (N=31) }\end{array}$} \\
\cline { 2 - 5 } & (n) & $\%$ & (n) & \% \\
\hline $\begin{array}{c}\text { Students } \\
\text { failing all Part } \\
\text { 2 exams }\end{array}$ & 3 & $7.5 \%$ & 0 & $0.0 \%$ \\
\hline $\begin{array}{c}\text { Students } \\
\text { passing grade } \\
\text { 1 exam }\end{array}$ & 37 & $92.5 \%$ & 31 & $100.0 \%$ \\
\hline $\begin{array}{c}\text { Students } \\
\text { passing grade } \\
3 \text { exam }\end{array}$ & 20 & $50.0 \%$ & 27 & $87.1 \%$ \\
\hline $\begin{array}{c}\text { Students } \\
\text { passing grade } \\
5 \text { exam }\end{array}$ & 1 & $2.5 \%$ & 2 & $6.5 \%$ \\
\hline $\begin{array}{c}\text { Average } \\
\text { percentage of } \\
\text { assignments } \\
\text { completed }\end{array}$ & & $35.2 \%$ & & $86.4 \%$ \\
\hline
\end{tabular}

All the students working in pairs passed the grade 1 exam. The students working independently did not achieve the same success. Instead, three of the independently working students failed the exam. The same trend occurred for the grade 3 exam: $87.1 \%$ of the pair working students passed the exam, but for the independent workers the ratio was $50 \%$. For the grade 5 exam, three students passed the exam, two working in pairs and one independently.

When doing assignments in pairs, both students working in pairs passed the assignment when one of them did it in the ViLLE system. The average percentage of assignments completed was $86.4 \%$ for the pair workers, compared to $35.2 \%$ for the independently working students.

The distributions of the exam grades between students were also analysed (see Table 2). The Mann-Whitney U Test with significance level of 0.05 revealed that the distributions of the Part 2 exam grades between the students working independently and in pairs were different $(p=0.001)$.

Table 2: Distribution of exam grades in Financing Mathematics

\begin{tabular}{|l|c|c|c|c|}
\hline \multirow{2}{*}{$\begin{array}{l}\text { Student } \\
\text { working }\end{array}$} & \multicolumn{4}{|c|}{ Exam Grade } \\
\cline { 2 - 5 } & $\mathbf{0}$ & $\mathbf{1}$ & $\mathbf{3}$ & $\mathbf{5}$ \\
\hline Independently & 3 & 20 & 16 & 1 \\
\hline In pairs & 0 & 4 & 25 & 2 \\
\hline
\end{tabular}

We also compared how many students passed the grade 1 and 3 exams at the first attempt (see Table 3 ). Table 3 shows that in the case of the grade 1 exams there was approximately $10 \%$ difference, but for the grade 3 exams the difference was almost $30 \%$. That is, the students working in pairs outperformed the independently working students at the first attempts of the grade 1 and 3 exams.

Table 3. Comparison of students' pass rates in the Financing Mathematics exams at the first attempt

\begin{tabular}{|l|c|c|c|c|}
\hline & \multicolumn{2}{|c|}{$\begin{array}{c}\text { Students } \\
\text { working } \\
\text { independently } \\
\end{array}$} & \multicolumn{2}{|c|}{$\begin{array}{c}\text { Students } \\
\text { working in pairs } \\
\text { (N=31) }\end{array}$} \\
\cline { 2 - 5 } (n) & \% & \multicolumn{2}{|c|}{ (n) } & $\%$ \\
\hline $\begin{array}{l}\text { Grade } \\
\text { 1 exam }\end{array}$ & 31 & $77.5 \%$ & 27 & $87.1 \%$ \\
\hline $\begin{array}{l}\text { Grade } \\
\text { 3 exam }\end{array}$ & 17 & $45.9 \%$ & 23 & $74.2 \%$ \\
\hline
\end{tabular}

For the analysis of the gender distribution, we found that the male students were divided quite evenly between the students working independently and in pairs (see Table 4). However, the female students mostly worked with the assignments independently. Additionally the table presents how the exam grades were distributed between students working independently and in pairs in Part 2.

Table 4. Gender distribution in Part 2 exams for independently and pair workers

\begin{tabular}{|c|c|c|c|c|c|}
\hline \multirow[b]{2}{*}{$\begin{array}{l}\text { Exam } \\
\text { grade }\end{array}$} & \multicolumn{2}{|c|}{ Female } & \multicolumn{2}{|c|}{ Male } & \multirow[b]{2}{*}{ SUM } \\
\hline & $\begin{array}{l}\text { Indep } \\
\text { enden } \\
\text { tly }\end{array}$ & $\begin{array}{l}\text { In } \\
\text { pair }\end{array}$ & $\begin{array}{l}\text { Indep } \\
\text { enden } \\
\text { tly }\end{array}$ & $\begin{array}{l}\text { In } \\
\text { pair }\end{array}$ & \\
\hline $\mathbf{0}$ & 0 & 0 & 3 & 0 & 3 \\
\hline 1 & 12 & 2 & 8 & 2 & 24 \\
\hline 3 & 8 & 6 & 8 & 19 & 41 \\
\hline 5 & 0 & 1 & 1 & 1 & 3 \\
\hline SUM & 20 & 9 & 20 & 22 & 71 \\
\hline
\end{tabular}

Table 4 reveals that for both genders, students working in pairs succeeded better than the independently working ones.

The course was taught in English that was foreign language for most of the students. Only few students were native English speakers. The teacher's native language was Finnish. For the comparison between Finnish and international students we analysed the exams grades of the independently working students and the students working in pairs (see Table 5).

Table 5 indicates that both Finnish and international students benefit from pair working. It seems that the nationality of the students does not affect to the results.

We expected that one important factor for better results was caused by the amount of time students spent with the assignments. 
Table 5. Comparison of Finnish and international student grades

\begin{tabular}{|c|c|c|c|c|c|}
\hline \multirow[b]{2}{*}{$\begin{array}{l}\text { Exam } \\
\text { grade }\end{array}$} & \multicolumn{2}{|c|}{ International } & \multicolumn{2}{|c|}{ Finnish } & \multirow[b]{2}{*}{ SUM } \\
\hline & $\begin{array}{l}\text { Indep } \\
\text { enden } \\
\text { tly }\end{array}$ & $\begin{array}{l}\text { In } \\
\text { pair }\end{array}$ & $\begin{array}{l}\text { Indep } \\
\text { enden } \\
\text { tly }\end{array}$ & $\begin{array}{l}\text { In } \\
\text { pair }\end{array}$ & \\
\hline $\mathbf{0}$ & 3 & 0 & 0 & 0 & 3 \\
\hline 1 & 11 & 3 & 9 & 1 & 24 \\
\hline 3 & 12 & 15 & 4 & 10 & 41 \\
\hline 5 & 1 & 2 & 0 & 0 & 3 \\
\hline SUM & 27 & 20 & 13 & 3 & 71 \\
\hline
\end{tabular}

Another related factor could be the amount of submissions students completed. The mean value for the amount of submissions by the students working in pairs was 54 , and the mean value for the time was 228 minutes per student. The mean values for students working in pairs were 91 submissions and 349 minutes per student. These calculations include all the 71 students.

However, when we further analysed the results by taking into account only the students with submissions in the assignment rounds the results were different (see Table 6).

Table 6. Comparison of submissions, students participations and time spend with assignments

\begin{tabular}{|l|c|c|c|c|c|}
\hline \multirow{4}{*}{} & \multicolumn{5}{|l|}{ Assignment rounds } \\
\cline { 2 - 6 } & 1. & 2. & 3. & 4. & Recap \\
\hline Independently working students (N=40) \\
\hline $\begin{array}{l}\text { Students } \\
\text { with } \\
\text { submissions }\end{array}$ & 33 & 20 & 16 & 13 & 18 \\
\hline $\begin{array}{l}\text { Participation } \\
\text { rate }\end{array}$ & $83 \%$ & $50 \%$ & $40 \%$ & $33 \%$ & $45 \%$ \\
\hline $\begin{array}{l}\text { Mean } \\
\text { amount of } \\
\text { submissions }\end{array}$ & 15 & 29 & 24 & 16 & 28 \\
\hline $\begin{array}{l}\text { Mean time } \\
\text { per round } \\
\text { (min) }\end{array}$ & 51 & 119 & 77 & 62 & 168 \\
\hline
\end{tabular}

\section{Students working in pairs $(\mathbf{N}=31)$}

\begin{tabular}{|l|c|c|c|c|c|}
\hline $\begin{array}{l}\text { Students } \\
\text { with } \\
\text { submissions }\end{array}$ & 31 & 30 & 23 & 26 & 23 \\
\hline $\begin{array}{l}\text { Participation } \\
\text { rate }\end{array}$ & $100 \%$ & $97 \%$ & $74 \%$ & $84 \%$ & $74 \%$ \\
\hline $\begin{array}{l}\text { Mean } \\
\text { amount of } \\
\text { submissions }\end{array}$ & 21 & 25 & 20 & 14 & 26 \\
\hline $\begin{array}{l}\text { Mean time } \\
\text { per round } \\
\text { (min) }\end{array}$ & 68 & 104 & 69 & 54 & 114 \\
\hline
\end{tabular}

Table 6 reveals that the mean values for the times spent with the assignments were similar between independently working students and students working in pairs, except in the case of the recap round: The independently working students worked longer with the recap assignments. However, the participations in the student groups were different. The students working in pairs outperformed independently working students: All 31 students submitted assignments in the $1^{\text {st }}$ round compared to $83 \%$ for the independently working students. In the $2^{\text {nd }}, 3^{\text {rd }}, 4^{\text {th }}$ and the recap rounds the differences were higher: $97 \%$ vs. $50 \%$; $74 \%$ vs. $40 \%$; $84 \%$ vs. $33 \%$; $74 \%$ vs. $45 \%$. The reason for these differences seems to be caused because of collaboration between the students.

\section{Discussion}

The students working in pairs achieved better results in the exams than the students working independently in the Financing part of the Business Mathematics course. All the failed students worked independently. The ratios of the students passing the grade 1, 3 and 5 exams were also better for the students working in pairs. This difference was the most significant in the case of the grade 3 exams. Accordingly, $74.2 \%$ of the students working in pairs passed the grade 3 exam at the first trial compared with $45.9 \%$ of the independently working students. This confirmed the hypothesis of this study that by working in pairs with ViLLE, students achieve better exam grades in Financing Mathematics. This supports the research findings about pair work for programming $[3,5,8,9]$.

The main reason for the improved results seemed to be the increased amount of the work the students working in pairs did with the assignments compared with the independently working students. The students working in pairs completed 50\% more assignments than the independently working ones. The amount of the collaborative work seems to be the key reason for the better success rates in exams for the treatment group.

Concerning the gender effect on the success of the pair work, we have not found evidence similar to the Maguire study [8] that females benefit more from the pair work. Instead, both males and females seemed to benefit from the pair work. Mathematics as such might be the reason for the different result as males typically tend to succeed in Mathematics better than females. Additionally, the students' home country appears not to have an effect on the results. Both Finnish and the international students benefit from pair working.

The results also revealed that students working in pairs participated more actively in the assignment rounds. The participation rate of the students working in pairs was $74 \%$ or larger in all the assignment rounds. The participation rate for independently working students decreased during the 
assignment rounds. This difference can be attributed to the collaboration between students. The pair working seems to have positive effect on students' activities.

There was no pre-test in the research. However, the sample size in the research data was over 70 students, and therefore the pre-test was not needed to prove the results. Nevertheless, a pre-test could improve the reliability of the study. Additionally, pairs could have been assigned randomly to further improve the reliability and validity of this study.

\section{Conclusion and future work}

The goal of this paper was to analyse the effect of collaborative testing with the e-assessment tool ViLLE on students' success in the Financing Mathematics exams. This study confirmed the effect: students working in pairs attain better grades.

We compared the exams' grades and the exam success rates of students working independently and in pairs with ViLLE. We also compared the ratio of the assignments completed by the student groups. We also analysed how the gender and students' home country affected success in exams.

The amount of assignment work completed seems to be the key reason for the better success of the pair working students. This may be attributed to the collaboration between students which is stimulated with the use of the ViLLE tool.

Based on this paper we can summarise the key benefits of collaborative work with educational tools:

- Pair work improves the learning of Financing Mathematics.

- Pass and participations rates of students are improved because of pair working.

- The gender or nationality seems not to have an effect to results. Instead, students benefits of the working in pairs independent of gender or nationality.

Pedagogical aspects relating to the educational tools were not considered in detail during this study. Instead the main focus was on the usage of the ViLLE tool with assessment. Therefore, it would be interesting to analyse the effect of pedagogy on, for instance, additional teacher's personal coaching and guidance effects compared to the feedback students receive only by the tools: It would be interesting to investigate whether there are any significant difference of students' learning results when the feedback and guidance is provided by the ViLLE tool and by the teacher, or ViLLE only.

It would be also interesting to carry out more research into the effect of collaborative work with the different group sizes and verify how the students' initial ability levels affect the learning results.

\section{References}

[1] Crisp, G. (2011). Teacher's Handbook on eAssessment. Transforming Assessment-An ALTC Fellowship Activity, 18. http://transformingassessment.co $\mathrm{m} / \mathrm{sites} /$ default/files/files/Handbook_for_teachers.pdf (Access Date: 10 November, 2015).

[2] Conejo, R., Barros, B., Guzmán, E., \& Garcia-Viñas, J. I. (2013). A web based collaborative testing environment. Computers \& Education, 68, pp. 440-457.

[3] Hahn, J. Mentz, E. and Meyer, L. (2009). Assessment Strategies for Pair Programming. Journal of Information Technology Education, 8, pp. 273-284.

[4] JISC (2010), Effective Assessment in a Digital Age, HEFCE, http://www.webarchive.org.uk/wayback/archive/ 20140614115719/http://www.jisc.ac.uk/media/documents/ programmes/elearning/digiassass_eada.pdf (Access Date: 18 December, 2015).

[5] Kaila, E., Rajala, T., Laakso, M.J., Linden, R., Kurvinen, E., Karavirta, V. and Salakoski, T. (2015). Comparing student performance between traditional and technologically enhanced programming course. In Proc. 17th Australasian Computing Education Conference (ACE 2015) Sydney, Australia. CRPIT, 160. D'Souza, D and Falkner, K. Eds., ACS. pp. 147-154.

[6] Kuikka, M., Laakso, M. J. \& Joshi M. (2016). The Effect of the Immediate Feedback by the Collaborative Education Tool ViLLE on Learning for Business Mathematics in Higher Education. Journal of Educational Technology Systems, 45(1), pp.34-49.

[7] Li, M., and B. Lam. "Cooperative learning." (2005), http://www.ied.edu.hk/aclass/Theories/cooperativelearning coursewriting_LBH\%2024June.pdf (2 January 2016).

[8] Maguire, P., Maguire, R., Hyland, P., \& Marshall, P. (2014). Enhancing collaborative learning using pair programming: Who benefits? AISHE-J: The All Ireland Journal of Teaching and Learning in Higher Education, $6(2)$.

[9] Rajala, T., Kaila, E., Holvitie, J., Haavisto, R, Laakso, M.-J. and Salakoski, T. (2011). Comparing the Collaborative and Independent Viewing of Program Visualizations. 41st ASEE/IEEE Frontiers in Education Conference. F3G-1. Rapid City: IEEE.

[10] Winkley, J., et al. "A Landscape Review of Eassessment." http://www.alphaplusconsultancy.co.uk/pdf/B ecta\%20-\%20Eassessment\%20Landscape\%20review\%20\%20Report\%20Final.pdf (Access Date: 10 November, 2015). 